

Vol. XIII, N 1 (2019) pp. 85-103

Recibido: 9 de abril, 2019

Aceptado: 1 de junio, 2019

\title{
PASTOR, ¿USTED EN QUÉ CREE? SOCIOLOGÍA DE LOS PROCESOS DE LIDERAZGO E INSTITUCIONALIZACIÓN EN IGLESIAS EVANGÉLICAS DE PEQUEÑA Y MEDIANA ESCALA
}

\section{Pastor, ¿what do you believe in? Sociology of the processes of leadership and institutionalization in evangelical churches of small and medium scale}

\author{
Mariela Mosqueira* \\ CEIL-CONICET, Argentina \\ marielamosqueira@gmail.com
}

por

\author{
Joaquín Algranti*** \\ CEIL-CONICET, Argentina \\ jalgranti@hotmail.com
}

\begin{abstract}
Resumen
Las ciencias sociales de la religión tienden a priorizar el punto de vista de los creyentes sobre el de los especialistas a la hora de explorar la vida interna de las iglesias y sus lógicas de funcionamiento. El objetivo del artículo consiste en analizar las representaciones de pastores y líderes evangélicos, en torno a las tareas que involucra su actividad cotidiana en iglesias de pequeña y mediana escala de la Argentina. El trabajo explora analíticamente tres dimensiones dominantes en el ejercicio del liderazgo pastoral: (a) los modos de acceso a posiciones de jerarquía y sus estrategias de profesionalización (b) la construcción de las iglesias como unidades religiosas-familiares y (c) las relaciones que se establecen con los miembros de la sociedad civil. En lo que respecta a la metodología, los resultados corresponden a una encuesta no probabilística realizada durante el 2017 en uno de los principales retiros de pastores de la Argentina.
\end{abstract}

Palabras claves: Liderazgo, Evangélicos, Familia, Sociedad Civil.

\footnotetext{
* Investigadora del Centro de Estudios e Investigaciones Laborales, Consejo Nacional de Investigaciones Científicas y Técnicas (CEILCONICET). Profesora de la Universidad de Buenos Aires.
}

\begin{abstract}
** Investigador del Centro de Estudios e Investigaciones Laborales, Consejo Nacional de Investigaciones Científicas y Técnicas (CEILCONICET). Profesor de la Universidad de Buenos Aires.
\end{abstract}

Revista Cultura \& Religión Vol. XIII, 2019 № 1 (enero-junio)

Cómo citar este artículo: Mosqueira, M. \&Algranti, J. (2019). "Pastor, ¿usted en qué cree? Sociología de los procesos de liderazgo e institucionalización en iglesias evangélicas de pequeña y mediana escala”. Revista Cultura \& Religión. Vol.

13(1). pp. 85-103. 


\begin{abstract}
The social sciences of religion tend to prioritize the viewpoint of believers over that of specialists in exploring the inner life of churches and their logics of functioning. The aim of this article is to analyze the representations of pastors and evangelical leaders, regarding their daily tasks and activities involves in small and medium - scale churches in Argentina. The paper aims to analytically explore three dominant dimensions in the exercise of pastoral leadership: (a) the ways of access to hierarchical positions and their strategies of professionalization (b) the construction of churches as religious-family units and (c) the emerging relationships with members of civil society. Regarding the methodology, the results correspond to a non-probabilistic survey conducted during 2017 in one of the main retreats of pastors of Argentina.
\end{abstract}

Keywords: Leadership, Evangelicals, Family, Civil Society.

\title{
Introducción
}

La posición del especialista religioso suele ser una posición opaca para las ciencias sociales, sobredeterminada teóricamente por dos tipos de reduccionismo preponderantes: por un lado, se la entiende como mero efecto de la organización burocrática y sus escalafones, es decir, en tanto producto de un cuerpo colegiado de funcionarios, que regulan su ejercicio y alcance de acuerdo a un sistema de creencias, doctrinas y liturgias consagradas que la restringen al cumplimiento de un puesto; y por el otro, se la ubica generalmente dentro de un encuadre institucional más amplio al que se lo imagina como un espacio rígido, predefinido, que constriñe considerablemente las posibilidades efectivas de acción e innovación profesional. De esta manera, las funciones sagradas y su horizonte de liderazgo aparecen bajo la lente de una coacción doble, la del cargo y la del contexto.

Es habitual, entonces, que las actividades regulares de los representantes de instituciones religiosas -es el caso, por ejemplo, de los sacerdotes, rabinos, pastores o imanesno sean analizadas en su complejidad práctica, sino inferidas directamente de las responsabilidades y obligaciones del rol que ostentan. Se otorga poca importancia a la experiencia cotidiana de los especialistas, es decir, a la producción de un mundo propio con sus sentidos compartidos y opiniones singulares, sus formas creativas y rutinarias del obrar, sus espacios intensivos de socialización, sus proyectos, apuestas y obstáculos insuperables. La actitud abstracta que se desentiende de las agencias institucionales suele también sobreponderar el principio activo de las prácticas de sacralización que despliega la cultura popular o las lógicas individuales de la espiritualidad contemporánea, haciendo del creyente y su acción social la única fuerza dinamizadora de los entornos e imaginarios religiosos. Es

Revista Cultura \& Religión Vol. XIII, 2019 № 1 (enero-junio)

Cómo citar este artículo: Mosqueira, M. \&Algranti, J. (2019). "Pastor, ¿usted en qué cree? Sociología de los procesos de liderazgo e institucionalización en iglesias evangélicas de pequeña y mediana escala”. Revista Cultura \& Religión. Vol.

13(1). pp. 85-103. 
preciso contribuir a la exploración sistemática de la posición -tantas veces incomprendidade los profesionales de lo sagrado y los encuadres objetivos que habitan.

El propósito de nuestro artículo consiste en analizar las representaciones de pastores y líderes, pertenecientes tanto al mundo pentecostal como al bautista, en torno a las tareas que involucra su actividad cotidiana en iglesias evangélicas de pequeña y mediana escala de la Argentina. Nos proponemos explorar analíticamente tres dimensiones dominantes en el ejercicio del liderazgo pastoral:

(a) La primera, identifica los modos de acceso a posiciones de jerarquía y sus estrategias de profesionalización. Esta dimensión nos va a permitir caracterizar los perfiles y trayectorias pastorales, sus bases económicas y circuitos de capacitación. Aquí se plantea el problema acuciante de las sucesiones, vale decir, la probabilidad de garantizar la continuidad, pero también la reinvención del programa institucional de la iglesia y sus fundamentos carismáticos en una nueva generación de líderes. Diversos perfiles de herederos potenciales - co pastores y colaboradores cercanos, hijos de sangre, líderes de jóvenes, referentes de iglesias anexas- conforman un espacio invisible de competencia por ocupar el lugar del elegido y las cualidades extraordinarias que rodean su cargo.

(b) La segunda, refiere a la construcción de las iglesias como unidades religiosofamiliares, cuya fuerza emergente, su éxito y continuidad dependen de la articulación creativa entre proyectos que combinan en proporciones casi idénticas elementos profesionales y domésticos que definen la vida interna del templo. Se trata de instituciones híbridas en donde la familia nuclear representa la estructura primaria de la iglesia en términos de responsabilidades, involucramiento e imagen pública.

(c) La tercera y última dimensión, contempla las relaciones que establecen los pastores y líderes con los miembros de la sociedad civil -por ejemplo, funcionarios públicos, políticos o medios de comunicación- que los contactan por diferentes motivos. Se construye en este intercambio una "agenda social" con fuerte anclaje territorial en donde se enuncian, jerarquizan y se diseñan intervenciones sobre un conjunto de temas relevantes para los miembros del templo y del barrio.

En lo que respecta a las bases empíricas y metodológicas de nuestro trabajo, los resultados que presentaremos corresponden a una encuesta realizada en el retiro nacional de pastores “Argentina Oramos por vos" desarrollado del 6 al 8 de junio de 2017, en la Ciudad de Mar del Plata, Provincia de Buenos Aires. Se trata de un estudio descriptivo con muestreo no probabilístico de tipo coincidental en locación central a partir de encuestas autoadministradas. Se obtuvieron 601 cuestionarios completos y procesables de los 1235 distribuidos in situ lo que significa una tasa alta de respuesta de $49 \%$.

El encuentro anual reúne en su mayoría a pastores, co pastores y líderes -y en menor grado a sus esposas, predicadores, evangelistas y misioneros- para abordar mediante conferencias y charlas temáticas los principales problemas relativos a la vida pastoral. Este evento surge en el 2001 y es significado por sus organizadores como una respuesta a un contexto de crisis social de la Argentina que repercute en las iglesias generando mayor

\section{Revista Cultura \& Religión Vol. XIII, 2019 № 1 (enero-junio)}

Cómo citar este artículo: Mosqueira, M. \&Algranti, J. (2019). "Pastor, ¿usted en qué cree? Sociología de los procesos de liderazgo e institucionalización en iglesias evangélicas de pequeña y mediana escala”. Revista Cultura \& Religión. Vol. 13(1). pp. 85-103. 
demanda de contención en las tareas de liderazgo con poblaciones vulnerables. Desde entonces, el retiro logró consolidarse, ampliar su convocatoria y especializar sus áreas de intervención, para transformarse finalmente en uno de los principales dispositivos de reflexión colectiva de los especialistas evangélicos sobre sí mismos ${ }^{1}$.

\section{Imágenes de la situación pastoral}

Desde su creciente visibilidad pública, a partir de los años 1980, la figura del pastor evangélico en la Argentina -y también en Latinoamérica- ha suscitado una multiplicidad de interrogantes vinculados a su origen social (Soneira, 1991 y 1994), sus estilos de vida, sus concepciones de la sociedad y de la política (Marostica, 1997; Miguez, 1998; Freston, 2001; Algranti, 2010; Carbonelli, 2011; García-Ruiz \& Michel, 2012, Semán, 2013), su formación teológica (Saracco, 1989; Wynarczyk, 2007; Panotto, 2017) y las estrategias de financiamiento de sus templos, por solo mencionar algunos de los principales tópicos de indagación. En lo que al discurso mediático concierne, estos interrogantes suelen ser enunciados desde la sospecha que despierta el lugar subalterno que ocupan estos grupos en el mapa religioso regional ${ }^{2}$. Por eso, han construido en respuesta verdaderas caricaturas del liderazgo evangélico, opacando las dinámicas y texturas de la autoridad religiosa en contextos cristianos no-católicos (Frigerio, 1993 y 2017; Carbonelli \& Mosqueira, 2008). El pastor es construido mediáticamente como una figura de dudosa procedencia que instrumentaliza la Biblia en toda su literalidad y riqueza simbólica para montar un engaño con ayuda de los medios técnicos. El resultado es una estafa a gran escala a partir del aprovechamiento de la miseria material, pero sobre todo intelectual con la que se identifica a los sectores populares. La crítica progresista completa este diagnóstico con la denuncia de la

\footnotetext{
${ }^{1}$ Dos tipos de productos culturales, de diferente naturaleza y proyección, extienden el territorio simbólico sobre el que se sostiene el evento. El primero de ellos, recrea la agenda social de base. Se trata del libro " 40 días de ayuno, oración y renovación personal" publicado por Del Reino Impresores (2015), en donde se describe la plataforma simultáneamente religiosa y social -y en consecuencia política- que resume el movimiento de pastores con el objetivo tácito de promover una serie de acuerdos internos respecto a la "transformación integral" de la nación frente a un contexto de crisis. El segundo, no se encuentra dirigido en principio a los liderazgos medios de iglesia, sino hacia el gran público al que se lo interpela con fines proselitistas. Nos referimos a la película "La deuda" (2013) de VSN Producciones, asociada a su vez a una de las principales mega-iglesias de la Argentina. Ella narra la historia de un jugador compulsivo en su punto más bajo y el modo en que un encuentro inesperado transforma completamente su vida. El cortometraje cuenta con la presencia de actores reconocidos del entorno artístico en un intento por desmarcar al proyecto de las referencias estrictamente evangélicas.

${ }^{2}$ Siendo América Latina mayoritariamente católica, los grupos evangélicos conforman la posición de primera minoría religiosa en gran parte de los países de la región. Tomando sólo algunos casos, estudios recientes señalan que los evangélicos en Brasil alcanzan el 27\%, el 11\% en Chile, el 5\% en Paraguay, el 20\% en Bolivia y el $12 \%$ en Perú (Latinobarómetro, 2017). En la Argentina, los evangélicos representan el $9 \%$ de la población en un contexto de mayoría católica $(76,5 \%)$ y presencia de los indiferentes religiosos (11,3\%) (Mallimaci, Esquivel \& Giménez Béliveau, 2015)
}

\section{Revista Cultura \& Religión Vol. XIII, 2019 № 1 (enero-junio)}

Cómo citar este artículo: Mosqueira, M. \&Algranti, J. (2019). "Pastor, ¿usted en qué cree? Sociología de los procesos de liderazgo e institucionalización en iglesias evangélicas de pequeña y mediana escala”. Revista Cultura \& Religión. Vol.

13(1). pp. 85-103. 
perspectiva políticamente conservadora de la actividad evangélica en la región en tanto agente de difusión cultural de los países centrales. Esta ilusión o delirio bien fundado, parafraseando a Durkheim (1992, p.212), existe simultáneamente como estereotipo y estigma, ambos descargan toda la fuerza colectiva de la opinión pública y el sentido común contra una de las principales expresiones de las minorías religiosas en la Argentina.

Con la finalidad de complejizar estas miradas reificantes y partiendo de los datos obtenidos de nuestro estudio, en lo que sigue nos enfocaremos en la descripción de: a) las características socio-económicas de los especialistas evangélicos encuestados, b) sus modos de acceso al liderazgo, c) las estrategias de profesionalización que despliegan y d) el modo en que se insinúa el antiguo problema de la sucesión del carisma.

En lo que respecta al primer punto, se observa que la distribución por sexo, edad, educación y estado civil de los pastores encuestados indica que son en su mayoría varones $(60,1 \%)$, de entre 40 y 65 años $(72,4 \%)$, con niveles de instrucción medios y bajos (hasta secundaria completa $63,7 \%)$ y casi todos casados $(91,2 \%)$ con hijos $(90,1)$. Esta tendencia sugiere que los liderazgos evangélicos estarían recayendo en hombres, cabezas de familia, provenientes de sectores populares; lo que indicaría que la autoridad religiosa emerge desde las mismas bases sociales en las que las iglesias evangélicas se extienden. Esto echaría por tierra los imaginarios dominantes que construyen a la totalidad de los líderes evangélicos como agentes geográfica y socialmente foráneos.

En sintonía con estos datos, la encuesta arroja que 6 de cada 10 pastores declaran complementar su labor pastoral con un trabajo rentado por fuera de la comunidad religiosa. Al ser consultados por el tipo de actividad que ejercen, la mitad (49.4\%) respondió ser independiente (trabajador manual o en oficios, comerciante o profesional), un tercio $(28,3 \%)$ afirmó tener una ocupación en relación de dependencia y el resto se identificó como jubilado $(9,2 \%)$ o ama de casa (3\%). De modo que los pastores que se ven impulsados a trabajar fuera de sus iglesias tienden a optar por actividades flexibles y autónomas que les permiten desarrollar su labor pastoral sin mayores interferencias. Es probable también que sus tareas económicas sean resignificadas como vehículos indirectos de evangelización.

Ahora bien, ¿por qué la mayoría de los líderes encuestados trabajan fuera de sus iglesias? ¿Acaso la actividad pastoral no está suficientemente remunerada como suele imaginarse desde el sentido común? En efecto, la encuesta muestra que sólo el 28,1\% de los pastores recibe un sueldo fijo por parte de sus organizaciones religiosas, mientras que el $24,3 \%$ obtiene ofrendas esporádicas por parte de la feligresía y el 42,3\% realiza su tarea pastoral ad honorem, es decir, sin percibir retribución económica alguna.

A contrapelo del sacerdote católico -contenido por una institución que lo sustenta materialmente a la vez que lo aísla de sus circuitos de sociabilidad primarios- la figura del especialista evangélico se erigiría como completamente intramundana y, en consecuencia, procedente de la dinámica social y familiar en que la misma trama religiosa se inserta, como desarrollaremos en el próximo apartado.

\section{Revista Cultura \& Religión Vol. XIII, 2019 Nº 1 (enero-junio)}

Cómo citar este artículo: Mosqueira, M. \&Algranti, J. (2019). "Pastor, ¿usted en qué cree? Sociología de los procesos de liderazgo e institucionalización en iglesias evangélicas de pequeña y mediana escala”. Revista Cultura \& Religión. Vol.

13(1). pp. 85-103. 
Este dinamismo, sin embargo, no debe conducirnos a proyectar globalmente una autoridad religiosa precaria, inestable o informal. Por el contrario, como veremos a continuación, nuestra investigación sugiere que este dinamismo potencia una multiplicidad de estrategias de profesionalización y, por lo tanto, estandarización de la actividad pastoral en Argentina.

Al indagar en los modos de acceso a los espacios de liderazgo, los especialistas encuestados indicaron que llegaron a ocupar lugares de jerarquía por decisión del pastor de la iglesia $(34,3 \%)$ o de la denominación religiosa ${ }^{3}(26,8 \%)$ o de la comunidad de fe $(12,6 \%)$ a la que pertenecían. Esto es, el 73,7\% de los líderes evangélicos encuestados accedieron a cargos de autoridad por mecanismos institucionales de selección. Sólo un 17\% se consagró pastor "por decisión propia". Estos datos complejizan aquellas imágenes anárquicas y cuentapropistas de la dirigencia cristiana no-católica en Latinoamérica. En todo caso, el denominado "pastor de garaje", es decir, las formas emergentes y autónomas de liderazgo que prescinden de los encuadres institucionales de formación, capacitación y monitoreo así como de las redes internacionales de sociabilidad que ofrecen las federaciones (Semán, 2010), coexistiría con un perfil de especialista que construye su carrera de acuerdo a las expectativas de un sacerdocio profesionalmente orientado por los espacios dominantes de titulación y reconocimiento ${ }^{4}$.

En esta misma línea, al ser preguntados por la formación adquirida para la tarea pastoral, el 65,6\% declaró haber estudiado en un seminario o instituto bíblico y un 10,5\% en ministerios de formación pastoral fuera de sus iglesias, mientras que el $24 \%$ indicó haber recibido instrucción de su propio pastor. Únicamente, el 5,2\% se definió autodidacta.

De modo que, la mayoría de líderes evangélicos que participan del retiro de pastores -“Argentina Oramos por vos"- acceden a espacios jerárquicos con algún tipo de entrenamiento formal, tendencia que sugeriría la consolidación de circuitos estables de capacitación pastoral y, consecuentemente, de profesionalización de la autoridad religiosa dentro un sector del mundo evangélico.

\footnotetext{
${ }^{3}$ Dentro del mundo evangélico, las denominaciones son organizaciones religiosas que nuclean iglesias. En general, funcionan con una estructura organizativa con desarrollo territorial y pregonan un tipo de doctrina o acento teológico específico.

${ }^{4}$ El caso fundacional del pastor Giménez, analizado por Soneira, Tort \& Pessina (1993) y Spadafora (2004), representa un modelo paradigmático de liderazgo evangélico en donde las experiencias, primero, de marginalidad, luego de empoderamiento y proyección religiosa confluyen en una misma trayectoria modelo para toda una generación del neo-pentecostalismo argentino. Lo que ocurrió simultáneamente durante la década de 1980 fue la profesionalización intensiva de la tarea pastoral cuyo alcance y consecuencias es posible reconocer en la presente investigación.
}

\section{Revista Cultura \& Religión Vol. XIII, 2019 № 1 (enero-junio)}

Cómo citar este artículo: Mosqueira, M. \&Algranti, J. (2019). "Pastor, ¿usted en qué cree? Sociología de los procesos de liderazgo e institucionalización en iglesias evangélicas de pequeña y mediana escala”. Revista Cultura \& Religión. Vol.

13(1). pp. 85-103. 


\section{Gráfico 1: Acceso al liderazgo y profesionalización.}

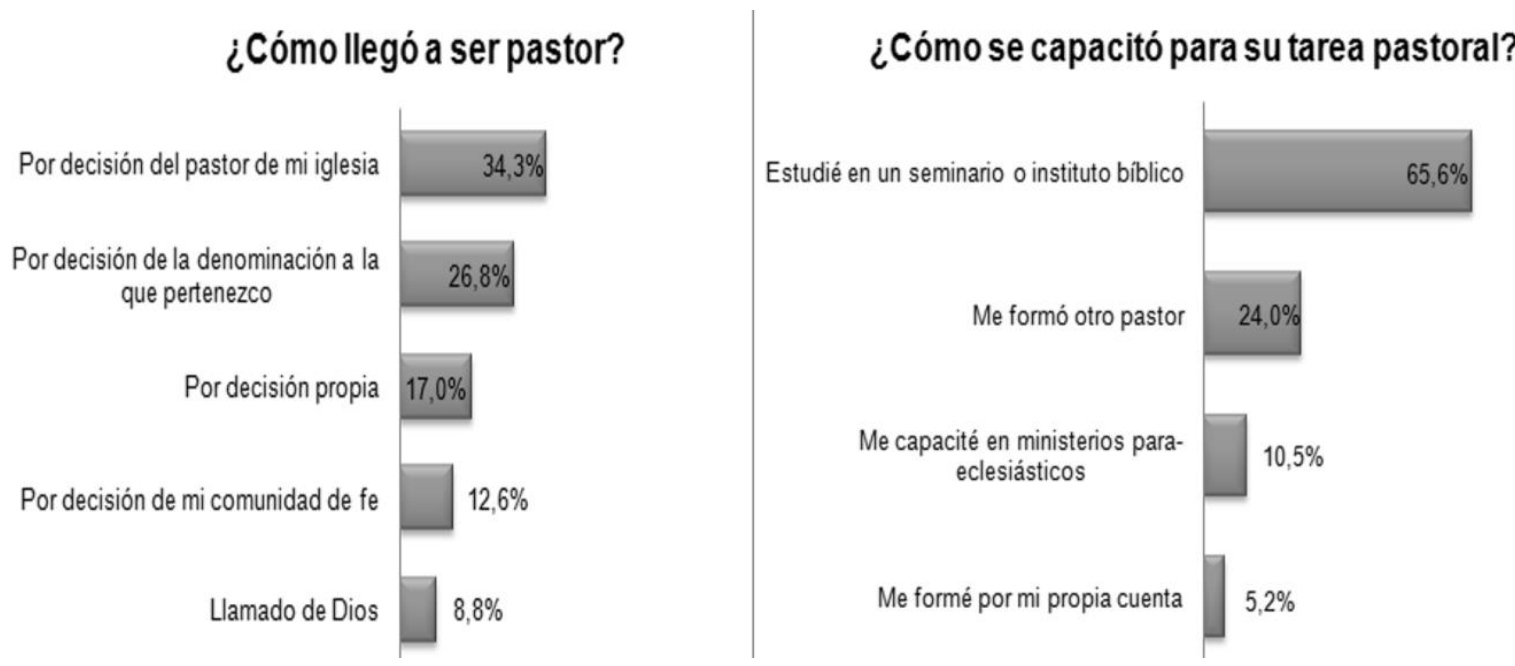

Base: Total entrevistados (601)

Fuente: Primera Encuesta Académica a Pastores y Líderes Evangélicos de Argentina

Finalmente, y en relación con lo expuesto, los datos relevados indicarían también cierta estandarización en los estilos de liderazgo a juzgar por las herramientas y materiales elegidos a la hora de actualizarse en la labor pastoral. Concretamente, los líderes afirman capacitarse leyendo libros (53,6\%); participando de jornadas, congresos o retiros pastorales $(45,8 \%)$ o consumiendo información circulante por internet $(20,7 \%)$ o programas de TV o radio $(8,3 \%)$.

La extensión y variedad de la cultura material evangélica refuerza un acervo de objetos espiritualmente marcados que participan de las distintas etapas de la vida religiosa de los líderes y contribuyen a la definición de situaciones concretas y sus posibles cursos de acción. El soporte simbólico de las tareas pastorales reconoce en los productos cristianos un espacio de referencia en donde se proponen tópicos, sensibilidades, estilos de comunicación y temas de estudio. Es evidente que la elección de mercancías, medios o eventos producidos en gran escala no solo nos estarían sugiriendo la difusión de estilos rutinizados de liderazgo, sino que también indicaría que son las industrias culturales ${ }^{5}$ emergentes de la comunidad religiosa uno de los vectores nucleares de dinamización y formateo de las estrategias de entrenamiento pastoral en la Argentina.

\footnotetext{
${ }^{5}$ Sobre industrias culturales evangélicas en América Latina véase Algranti (2018); Garma Navarro (2000); Mosqueira (2016); Miguel (2013); Silveira Campos (2012); Mansilla Agüero (2006 y 2009); entre otros.
}

\section{Revista Cultura \& Religión Vol. XIII, 2019 № 1 (enero-junio)}

Cómo citar este artículo: Mosqueira, M. \&Algranti, J. (2019). "Pastor, ¿usted en qué cree? Sociología de los procesos de liderazgo e institucionalización en iglesias evangélicas de pequeña y mediana escala”. Revista Cultura \& Religión. Vol.

13(1). pp. 85-103. 
El cuadro de la situación pastoral se completa con el problema complejo de la sucesión. ¿Quién continúa la tarea de los iniciadores? ¿Qué ocurre con las cualidades extraordinarias del líder, con los milagros, las sanaciones y el entorno carismático que delimita el templo? En relación a este tema, cabe señalar que el 60,9\% de los encuestados declaró no haber "levantado" todavía ningún pastor sucesor que lo reemplace en su tarea. Esta tendencia presenta variaciones significativas según tamaño y antigüedad de las organizaciones. En las iglesias chicas (hasta 100 miembros) se incrementa más de 20 puntos porcentuales, disminuyendo a 43,5\% en iglesias medianas (hasta 1000 miembros), a $42 \%$ en grandes (más de 1000 miembros) y a 51,8\% en las de mayor antigüedad (más de 16 años).

La construcción de un heredero portador del carisma es un trabajo que depende no sólo de la legitimidad de origen de los pretendientes, de los ritos de pasaje y los actos de nominación, sino también del reconocimiento y la aprobación severa de los seguidores que confirmen tanto la potencia como la autoridad que la persona ungida procura adjudicarse. El problema de la sucesión del carisma, tempranamente tematizado por Max Weber (1998, p.193), recae en el mundo evangélico dentro de las redes de confianza más intensas y constantes del pastor, las cuales tienden a coincidir -dada la estructura domestica de su organización- con la familia nuclear ${ }^{6}$.

\section{La iglesia como empresa familiar}

Una de las características distintivas que permite comprender la emergencia y la multiplicación de templos evangélicos en la Argentina, y posiblemente también en buena parte de América Latina, es la conformación de las iglesias -en todas sus escalas- como unidades cuya estructura responde a criterios religiosos y domésticos. La familia del pastor representa uno de los núcleos centrales sobre los que se construye la asociación espiritual ${ }^{7}$.

De hecho, la familia interviene en tres momentos claves de la organización interna de los templos: (a) en la decisión profesional de seguir el pastorado y establecer una iglesia propia. Esta elección puede materializarse a través de la capacitación, el estudio y los seminarios bíblicos, puede desarrollarse también por medio de la inspiración personal o es posible que ambos registros se combinen estratégicamente a lo largo de una misma carrera; (b) en el funcionamiento cotidiano del templo y en el estilo de vida que supone hacer de la familia un modelo pastoral de alta visibilidad, exposición y monitoreo por parte de los feligreses y (c) en el momento de la sucesión del liderazgo una vez que la autoridad principal se retira de las funciones directivas y debe nombrar a una persona que continúe y, en cierta

\footnotetext{
${ }^{6}$ Para un desarrollo más amplio de los procesos carismáticos en las disputas por el liderazgo evangélico ver Campos \& Mauricio Junior (2013) y Ceriani Cernadas (2014). También es posible complejizar las comprensiones occidentales de dicho concepto con el libro de Feuchtwang (2010).

${ }^{7}$ Sobre la importancia de la estructura familiar en la configuración del mundo evangélico y religioso ver Campos Machado (1996); Duarte, Heilborn, Lins de Barros \& Peixoto (2006); Giménez Béliveau \& Mosqueira (2011); Zaros (2016); Espinosa \& Bargo (2016).
}

Revista Cultura \& Religión Vol. XIII, 2019 № 1 (enero-junio)

Cómo citar este artículo: Mosqueira, M. \&Algranti, J. (2019). "Pastor, ¿usted en qué cree? Sociología de los procesos de liderazgo e institucionalización en iglesias evangélicas de pequeña y mediana escala”. Revista Cultura \& Religión. Vol. 13(1). pp. 85-103. 
medida, relance el proyecto carismático sobre el que se construye toda organización. En otros términos, podemos decir que la estructura doméstica participa en la emergencia, la reproducción y las posibilidades -siempre inciertas- de continuidad de las iglesias.

Nuestra investigación muestra la acción continua de las relaciones domésticas en las más variadas tareas, funciones y proyecciones de la vida interna de los templos. El 90,7\% de los encuestados afirma haber recibido el respaldo de su familia a la hora de optar por una profesionalización en el ejercicio pastoral. A su vez, las iglesias que conducen cuentan en el $88,4 \%$ de los casos con la participación de los cónyuges en funciones mayoritariamente directivas del ministerio: $65,7 \%$ es pastor o pastora, $35,2 \%$ se desempeña como líder y un $12,4 \%$ realiza labores administrativas o de colaboración general.

Lo más probable es que, sobre todo en las iglesias pequeñas y medianas, los cónyuges participen indistintamente en cada una de las actividades desde las más rutinarias e invisibles, como preparar las sillas del culto o el equipo de música, hasta las más prestigiosas, tal es el caso, de la prédica central o la conducción de la alabanza. La ideología del servicio, la humildad y su escenificación pública vuelve compatible la participación de las figuras de autoridad en todo tipo de responsabilidades, incluso aquellas de menor estatus asociadas generalmente a los nuevos miembros de la congregación.

Los altos porcentajes de participación doméstica se expresan además en el involucramiento de los hijos de los pastores y líderes en los espacios de trabajo de la iglesia. El $81 \%$ de los encuestados declaran contar con su servicio. Es interesante destacar que, aunque en menor medida, también mencionan a otros parientes como equipo colaborador: yernos y nueras $(11,8 \%)$, los padres o suegros $(10,5 \%)$ y, también, sus hermanos $(9,7 \%)$.

Entre las funciones que ejercen la familia nuclear y la ampliada tienden a imponerse dos espacios predilectos de acción. Por un lado, las formas de liderazgo dirigidas a la juventud, la escuela bíblica y el trabajo con los niños representan el $62 \%$ de las ocupaciones realizadas por los familiares. Por otro lado, sobresale con un 50,4\% el ejercicio de tareas relativas a la música dentro del ministerio de alabanza y adoración. Podemos reconocer en menor escala las actividades administrativas (10,5\%), las técnicas (10,3\%), las pastorales $(7,8 \%)$ y, en último término, la presencia como miembro de la feligresía (4,2\%). El liderazgo, la enseñanza, la música y la juventud, es decir, las áreas relacionadas fuertemente a la trasmisión y renovación del mensaje espiritual son los campos de acción por excelencia de las nuevas generaciones (Mosqueira, 2014; Lago, 2018).

Es pertinente señalar que en tanto unidades simultáneamente religiosas y domésticas, los templos no pueden prescindir de las intervenciones continuas de la familia del pastor. A su vez, las estructuras espirituales y las estructuras de parentesco se retroalimentan produciendo una asociación indisoluble. El acompañamiento familiar permite sostener el ejercicio de una profesión altamente demandante y desregulada que carece de un encuadre institucional con una idea fija de carrera, ascenso, salario o contrato, un uso del tiempo preestablecido o una distinción entre los momentos de ocio y de actividad. El pastor es pastor todo el día y en cada cosa que hace.

\section{Revista Cultura \& Religión Vol. XIII, 2019 № 1 (enero-junio)}

Cómo citar este artículo: Mosqueira, M. \&Algranti, J. (2019). "Pastor, ¿usted en qué cree? Sociología de los procesos de liderazgo e institucionalización en iglesias evangélicas de pequeña y mediana escala”. Revista Cultura \& Religión. Vol.

13(1). pp. 85-103. 
La empresa estrictamente religiosa requiere entonces de la familia a modo de un marco que regula las actividades cotidianas, produciendo en el mismo movimiento el efecto inverso, es decir, la sacralización de las estructuras de parentesco en donde la esposa y los hijos del pastor son testimonio y prueba de la calidad espiritual del líder, de su santificación.

$\mathrm{Su}$ visibilidad es un aspecto decisivo de la imagen pública que suscita esta forma de liderazgo religioso. Lo mismo ocurre, pero en menor grado, con otros valores de referencia como la prosperidad material que se expresa en el modo de vestir, la decoración del templo o el estado de salud y funcionan como indicadores indiscutidos de bendición y ungimiento.

Las asociaciones domestico-religiosas enfrentan, también, problemas directamente relacionados con el tipo de organización que construyen: las conductas, decisiones y desempeños de la familia cercana del pastor no son sólo un soporte de su práctica, sino a su vez un objeto de escrutinio público por parte de la comunidad. Esta última integra los dones espirituales de su líder, la potencia y autenticidad de su carisma, con los vínculos de parentesco que lo rodean. Su estima y prestigio dependen de ello.

En efecto, nuestra encuesta sugiere que una de las preocupaciones centrales del liderazgo evangélico son las murmuraciones y habladurías. Esto es, 5 de cada 10 pastores y líderes identifica a los "chismes y divisiones internas" como el principal problema de sus iglesias. De ahí que el llamado "chisme santo", la crítica y la difamación representen temas recurrentes a los que se sanciona moralmente durante las prédicas del culto. Las murmuraciones sobre la vida matrimonial del pastor, el comportamiento de sus hijos o la historia de sus padres y parientes son una forma corriente de desprestigiar la institución que conduce y su capacidad de erigirse como un canal efectivo de lo sagrado.

En base a conocimientos previos de naturaleza cualitativa es posible reconocer que esta mirada social que permanentemente monitorea y evalúa a las posiciones de autoridad y sus familias, hace de la función religiosa una de las ocupaciones más estresantes. Justamente, nuestra encuesta recoge que el 52,3\% de los pastores y líderes identifican al estrés como la problemática más recurrente de la labor pastoral y, al ser consultados por el impacto de la tarea eclesiástica en su salud, el 55,3\% declaró haber experimentado síntomas de agotamiento físico, mental y emocional.

Revista Cultura \& Religión Vol. XIII, 2019 Nº 1 (enero-junio)

Cómo citar este artículo: Mosqueira, M. \&Algranti, J. (2019). "Pastor, ¿usted en qué cree? Sociología de los procesos de liderazgo e institucionalización en iglesias evangélicas de pequeña y mediana escala”. Revista Cultura \& Religión. Vol. 13(1). pp. 85-103. 


\section{Gráfico 2: La iglesia como empresa familiar}

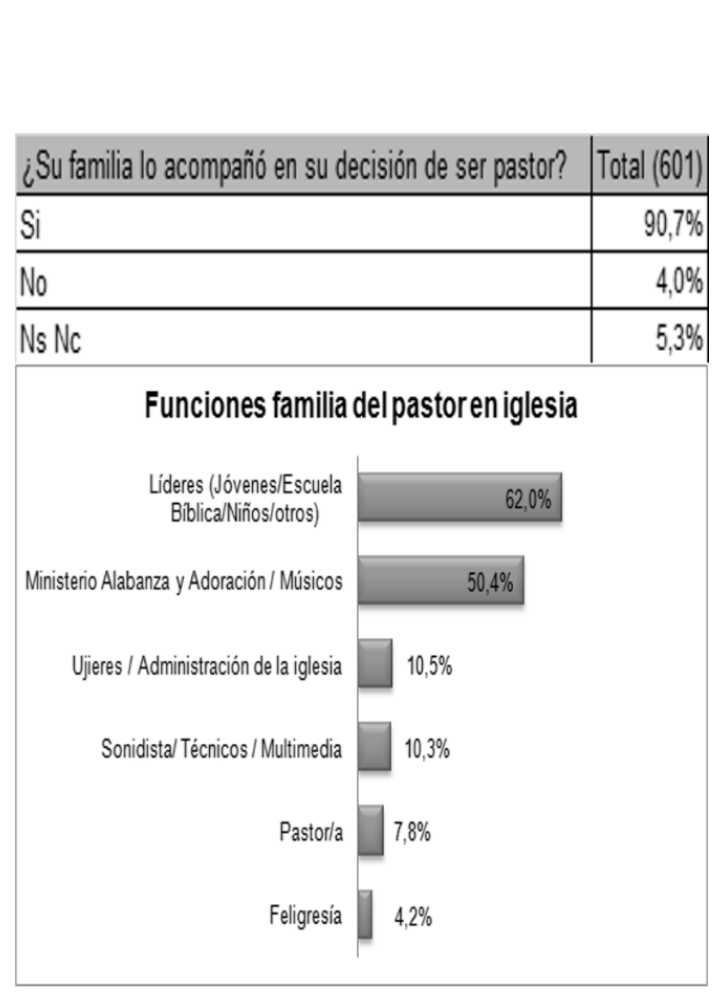

Base: Total entrevistados (601)

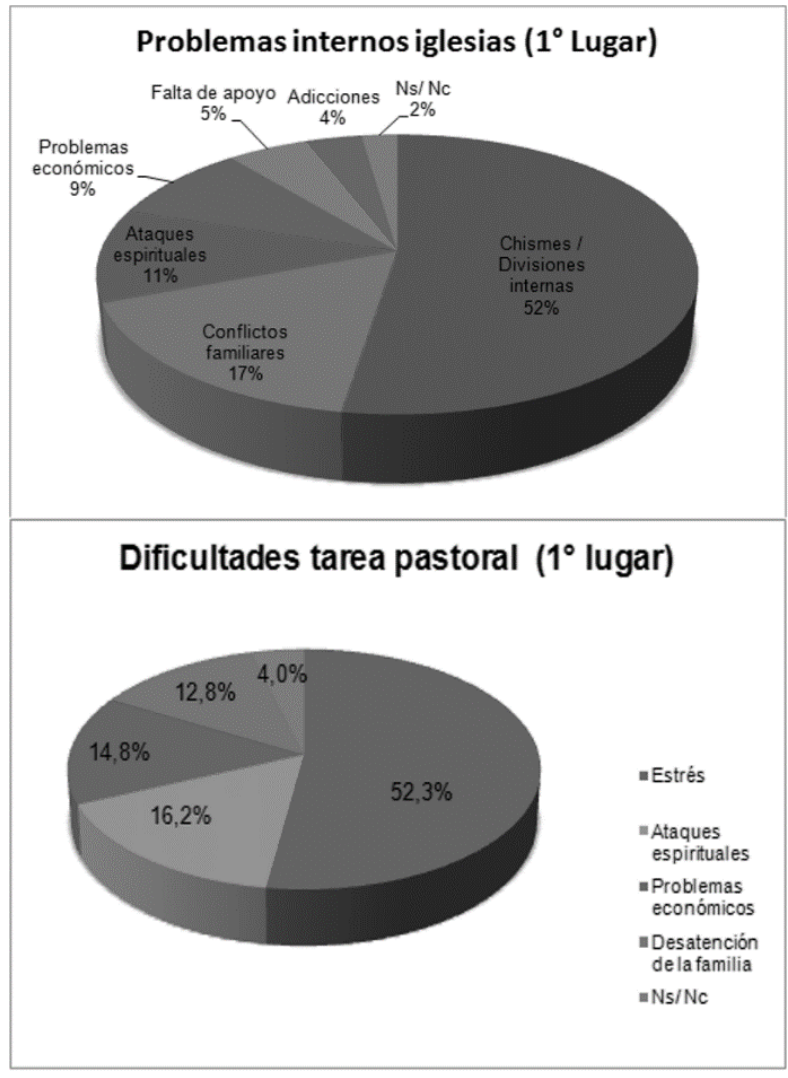

Fuente: Primera Encuesta Académica a Pastores y Líderes Evangélicos de Argentina

Por lo tanto, la estructura doméstica sería uno de los vectores claves para entender las dinámicas de emergencia y consolidación de los liderazgos evangélicos en la Argentina. Su potencia estabilizante y, a su vez, flexible hace a la constitución vertiginosa pero también al mantenimiento de las iglesias en sus actividades cotidianas. La destreza con la que desde las mismas estructuras parentales se producen organizaciones, estilos de liderazgo y conducción reforzaría simultáneamente el anclaje territorial y social de estos grupos religiosos. Siguiendo nuestro análisis es importante explorar los vínculos que se establecen con la sociedad civil, esto es, con las problemáticas locales, los grupos de referencia y las áreas de impacto de los pastores en sus zonas de influencia.

\section{Revista Cultura \& Religión Vol. XIII, 2019 N 1 (enero-junio)}

Cómo citar este artículo: Mosqueira, M. \&Algranti, J. (2019). "Pastor, ¿usted en qué cree? Sociología de los procesos de liderazgo e institucionalización en iglesias evangélicas de pequeña y mediana escala”. Revista Cultura \& Religión. Vol.

13(1). pp. 85-103. 


\section{El Evangelio en el barrio}

Las funciones y ejercicios del liderazgo delimitan un territorio propio que incluye fácilmente a las proximidades de la iglesia entre sus áreas de intervención. El barrio, con sus circuitos, regiones y espacios móviles describe la geografía ampliada del templo en donde transcurren las rutinas y sociabilidades de los creyentes. No es extraño entonces que el Evangelio sea una metáfora actualizada, a veces un eufemismo, de las formas de vida y los juegos del lenguaje que gobiernan el ritmo cotidiano de los suburbios. Las preocupaciones, anhelos e intereses, las sensibilidades y demandas de un mundo social determinado encuentran puntos de identificación con las modalidades expresivas y las imágenes simbólicas que perfeccionan los pastores.

Los encuestados reconstruyen un punto de vista propio sobre las principales problemáticas que identifican en las cercanías de su templo. A partir de una pregunta abierta, esto es, sin opciones predeterminadas y con la posibilidad de reconocer hasta tres respuestas, los pastores y líderes jerarquizaron las dificultades que encuentran en su barrio que en su mayoría identificaron como perteneciente a sectores de bajos ingresos (62.1\%). Su criterio de orden tiende a priorizar cuestiones sociales relativas: primero, a las "adicciones" (59,9\%); en segundo lugar, "la inseguridad, los hechos de violencia y corrupción" (49,4\%); seguida por la "pobreza, la falta de educación y trabajo" $(39,3 \%)$ y a continuación, "la familia, la violencia doméstica y la infidelidad" (29,5\%). Recién en el quinto puesto, se ubican los asuntos de naturaleza espiritual vinculados a la "idolatría, los legalismos, la religiosidad y la brujería" (28,8\%); la lista se prolonga con la "apatía y el desánimo" $(25,8 \%)$ y en escalas considerablemente menores tanto los "abusos, la prostitución y la sexualidad" $(7,2 \%)$ como los problemas que conciernen a los "jóvenes, la niñez y los adultos mayores" $(6,3 \%)$.

Investigaciones previas de impronta cualitativa nos permiten enunciar una hipótesis de lectura para interpretar el orden y las funciones de los tópicos que priorizan los encuestados. Es probable que la dominancia de los motivos sociales cuyo epicentro son la díada "adicción-inseguridad" sea considerada como el efecto o la consecuencia de una crisis preexistente tanto en las condiciones de vida (trabajo, educación, pobreza) como en la familia (violencia doméstica e infidelidad) y que a su vez esta crisis responda, en última instancia, a un alejamiento de Dios. En una palabra, el lugar subordinado de las cuestiones religiosas no quita que cada una de las problemáticas sociales puede espiritualizarse a través de una raíz cosmológica común. Asimismo, la maestría en el manejo de los problemas territoriales, prácticos, del creyente y su entorno, sitúa a los líderes como expertos reconocidos en sus zonas de influencia. En analogía con el saber técnico del sociólogo, el político o el trabajador social, los pastores construyen una corriente de opinión y una imagen de sí mismos como interpretes autorizados del mundo que los ocupa.

Ahora bien, ante este diagnóstico de situación ¿con qué áreas conflictivas trabajan en sus ámbitos de influencia? Aunque las adicciones son consideradas el mayor de los problemas que acucia al barrio -al igual que los hechos de inseguridad y violencia-, los

\section{Revista Cultura \& Religión Vol. XIII, 2019 № 1 (enero-junio)}

Cómo citar este artículo: Mosqueira, M. \&Algranti, J. (2019). "Pastor, ¿usted en qué cree? Sociología de los procesos de liderazgo e institucionalización en iglesias evangélicas de pequeña y mediana escala”. Revista Cultura \& Religión. Vol.

13(1). pp. 85-103. 
templos encuentran todo tipo de obstáculos -en especial de orden interno- a la hora de abordarlas y cuando lo hacen a través de un ministerio en particular, éste suele mantener una posición periférica o relegada respecto a la vida interna de la congregación (Algranti y Mosqueira, 2018). La drogodependencia y el crimen son mayoritariamente asuntos de contexto, que participan de la iglesia cuando afectan en algún sentido a los núcleos familiares de su comunidad. El área más importante de intervención de las iglesias compete sin duda a la familia y sus relaciones $(86,0 \%)$, luego y con un amplio margen de diferencia, los encuestados reconocen las problemáticas sociales $(52,1 \%)$, el trabajo individual con el sufrimiento, la enfermedad o malestar del sujeto $(49,0 \%) \mathrm{y}$, por último, los asuntos de índole estrictamente espiritual $(33,9 \%)$.

\section{Gráfico 3: Sociedad}

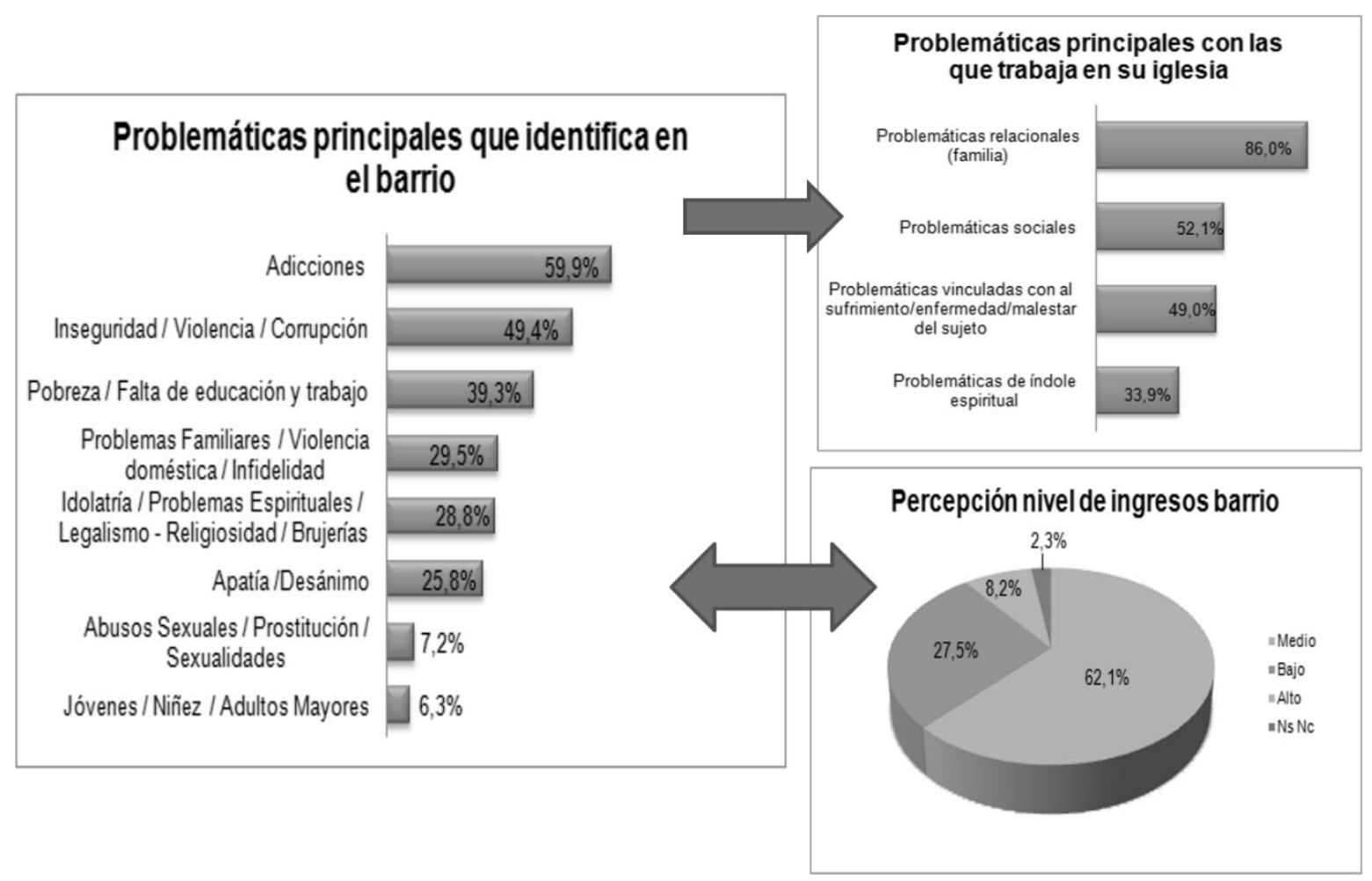

Base: Total entrevistados (601)

Fuente: Datos propios

La iglesia es una asociación de fines sagrados que oscila entre el individuo, su familia y las circunstancias que los rodean, pero que concentra su expertise profesional en el mundo de relaciones del creyente con su entorno inmediato. El modo en que se interpela y distingue

\section{Revista Cultura \& Religión Vol. XIII, 2019 № 1 (enero-junio)}

Cómo citar este artículo: Mosqueira, M. \&Algranti, J. (2019). "Pastor, ¿usted en qué cree? Sociología de los procesos de liderazgo e institucionalización en iglesias evangélicas de pequeña y mediana escala”. Revista Cultura \& Religión. Vol.

13(1). pp. 85-103. 
a los asuntos de la vida privada en tanto espacios de interés religioso, obedece en parte a la misma estructura doméstica de una institución que se funda, actúa y se piensa a si misma desde la familia.

El anclaje territorial de los templos hace que se tornen atractivos a los posibles contactos de miembros específicos de la sociedad civil. Se destacan los funcionarios públicos $(51,4 \%)$ así como los políticos de diferente rango y signos partidarios $(43,1 \%)$; con más de diez puntos de diferencia, aparecen las organizaciones sociales $(30,6 \%)$ y los medios de comunicación $(30,3 \%)$. La lista se completa con los pastores y líderes que declaran nunca haber sido contactados $(19,6 \%)$, los que señalan el trato con empresarios $(18,3 \%)$, con otras organizaciones religiosas $(15,5 \%)$ y asociaciones médicas $(9,5 \%)$. Los motivos de dichos intercambios responden mayoritariamente a la necesidad de asesorías (34,3\%), en temas en los que se especializa el templo (es el caso, de la familia, la violencia doméstica, las adicciones, los dilemas ético-morales y los valores); luego los asuntos relativos a las tareas de ayuda social $(28,1 \%)$, la organización conjunta de eventos $(17,6 \%)$, por pedidos de oración $(12,6 \%)$, campañas políticas $(9,8 \%)$, inspecciones y trámites $(5,7 \%)$ y temas educativos $(2,3 \%)$.

\section{Gráfico 4: Sociedad}

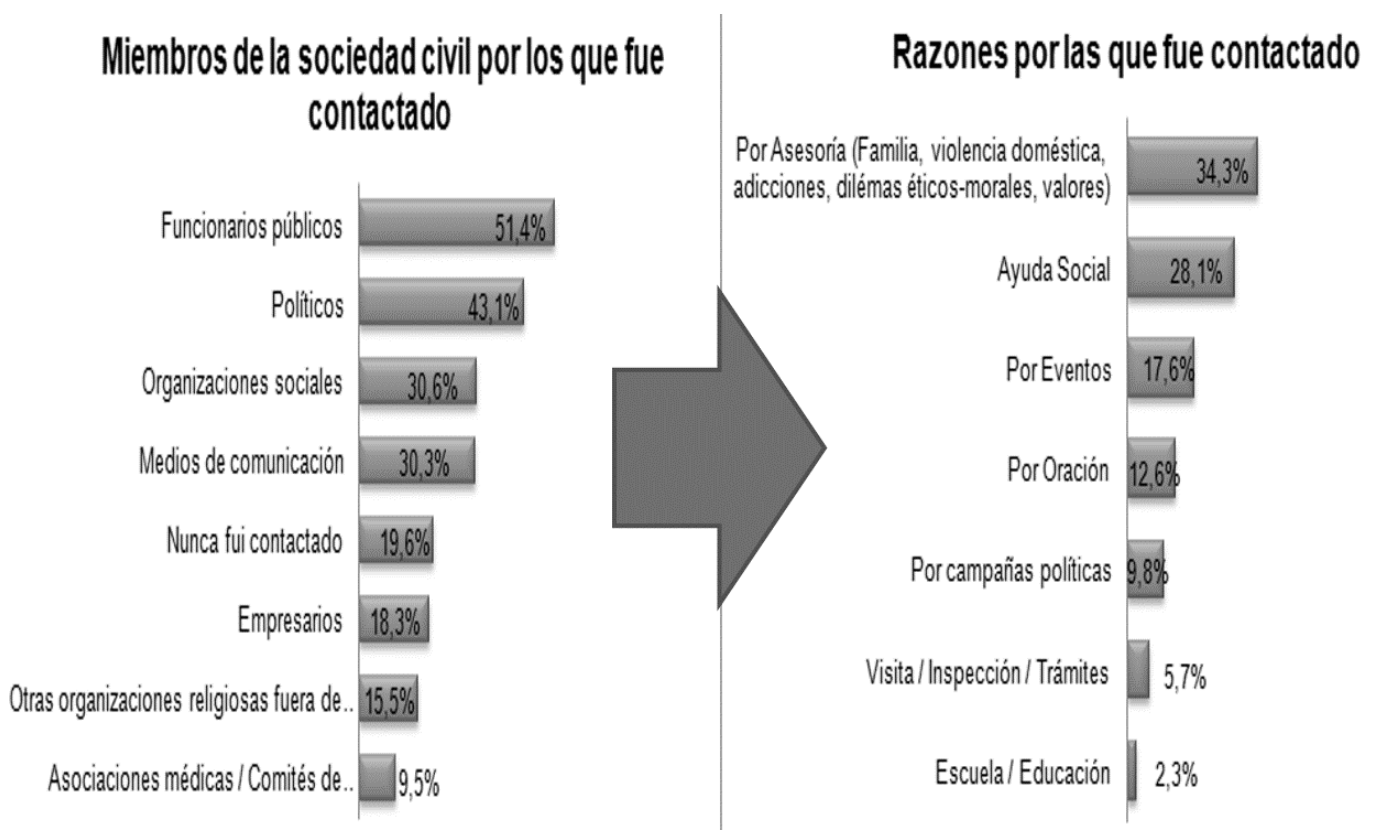

Base: Total entrevistados (601)

Fuente: Datos propios

Revista Cultura \& Religión Vol. XIII, 2019 № 1 (enero-junio)

Cómo citar este artículo: Mosqueira, M. \&Algranti, J. (2019). "Pastor, ¿usted en qué cree? Sociología de los procesos de liderazgo e institucionalización en iglesias evangélicas de pequeña y mediana escala”. Revista Cultura \& Religión. Vol.

13(1). pp. 85-103. 
En la representación de los pastores y líderes encuestados su iglesia es especialmente valorada por las autoridades públicas, también por los políticos -ya sea en funciones o en campaña-, por las organizaciones sociales y la prensa. No habría que descuidar el hecho de que los especialistas evangélicos suelen construir una imagen de sí mismos como asesores privilegiados en asuntos de gobierno así como referentes o consejeros morales en los más variados debates de la opinión pública. En cualquier caso, ya sea como realidad o deseo, el imaginario profesional de los pastores, sus actividades, servicios y competencias, es indisociable de una relación no sólo con los intereses cotidianos del barrio, sino a su vez con los centros de poder y decisión de los miembros de la sociedad civil que los contactan.

Del encuentro entre ambos mundos de sentido, es decir, entre los templos y las organizaciones civiles y públicas, surge cíclicamente el proyecto de construir una agenda socio-religiosa en torno a un conjunto de temas importantes, urgentes, a los que se identifica y formula como decisivos para la sociedad (la atención sobre la familia, las adicciones, la violencia, la pobreza, etc.). Se trata de un esfuerzo sostenido por establecer grandes consensos capaces de integrar la dispersión endémica del entramado evangélico y la multiplicidad de sus perfiles carismáticos, relanzando sus posibilidades de acción colectiva. Las proyecciones de acuerdo, unidad, movilización, nombran precisamente aquello de lo que carecen los procesos de liderazgo cristiano en la Argentina. Existe un hiato entre el anclaje territorial de los templos en donde se destaca la eficacia e impacto de sus tareas y las posibilidades efectivas para traducir esa fuerza dentro de las instituciones públicas no de manera episódica, ni circunstancial, sino permanente bajo la lógica del reconocimiento, el estatuto jurídico, el sostén económico; en una palabra, en los mismos términos que la iglesia católica y la suma de privilegios históricos que la distingue sobre el resto de los cultos. El Evangelio en el barrio es una fórmula tan exitosa como circunscripta. Por su parte, el Evangelio en el Estado representa en la imaginación de pastores y líderes una meta común, un horizonte de acción hecho a la medida de las aspiraciones, también las posibilidades, de una de las minorías religiosas más dinámicas de la Argentina.

\section{Conclusiones: ni burocratización, ni cuentapropismo}

El análisis cuantitativo nos permite identificar simultáneamente aspectos estructurales y corrientes de opinión que componen a una parte significativa del liderazgo evangélico. Asimismo, el uso reflexivo de los instrumentos de estudio nos lleva a reconocer que la encuesta gana en amplitud lo que pierde, a su vez, en la profundidad con la que se abordan otras dimensiones formativas de la vida social como, por ejemplo, los problemas de sentido o el principio de complejidad que gobierna a las prácticas y sus circunstancias. A sabiendas de las posibilidades y limitaciones epistemológicas del método elegido nos proponemos reunir en pocas palabras los principales hallazgos del artículo.

El estudio contribuye al análisis crítico de dos premisas dominantes en la comprensión de los especialistas religiosos: la primera describe a aquella que reduce sus

\section{Revista Cultura \& Religión Vol. XIII, 2019 № 1 (enero-junio)}

Cómo citar este artículo: Mosqueira, M. \&Algranti, J. (2019). "Pastor, ¿usted en qué cree? Sociología de los procesos de liderazgo e institucionalización en iglesias evangélicas de pequeña y mediana escala”. Revista Cultura \& Religión. Vol.

13(1). pp. 85-103. 
competencias al ejercicio formal de un rol doblemente condicionado por el cuerpo de profesionales que lo habilita y el encuadre institucional en donde desempeña sus funciones. Emulando versiones tan abstractas como esquemáticas del funcionalismo, los líderes y su mundo social aparecen bajo este punto de vista como epifenómenos de las burocracias sacerdotales. La segunda constituye el reverso de la primera, corresponde a la premisa que hace de los liderazgos realidades exclusivamente espontáneas, desreguladas, expresiones de la creatividad, el ingenio autodidacta y de las resistencias contraculturales de la religiosidad popular. No es el enfoque funcionalista sino los abordajes interpretativos, cercanos a los estudios culturales los que refuerzan los fundamentos de esta lectura. Ambas perspectivas cuentan con potencial heurístico en la medida en que se constituyan en hipótesis de investigación, no en supuestos, prenociones o grandes diagnósticos de época, cuya fuerza radica en la naturaleza incuestionada y la inercia de sus fundamentos.

La distancia crítica respecto a las formas del sentido común en las ciencias sociales y su efecto de opacidad, nos lleva a reconstruir un panorama diferente de los procesos de liderazgo evangélico que rompe con la antinomia burocracia-cuentapropismo. Cabe preguntarse entonces, ¿cómo surgen los espacios de culto y sus referentes?

La génesis de iglesias y pastores es la resultante de tres fuerzas que gravitan con intensidad variable en las tramas socioculturales de los sectores menos favorecidos: (a) la primera, plantea el encuentro entre la voluntad individual de organizar la biografía en torno a principios religiosos y el carácter legítimo, incluso prestigioso, que puede adoptar este curso de acción; (b) la segunda corresponde al soporte de una estructura doméstica que hace de la empresa un proyecto familiar y (c) la tercera, consiste en los mecanismos de seleccióncapacitación que acompañan, regulan y reconocen socialmente al pastorado. La naturaleza mayoritariamente semi-profesional de esta actividad incluye la articulación de las tareas sacerdotales con oficios flexibles que completan la base material de la iglesia. En contrapartida, la estructura domestica de las organizaciones expone a los especialistas y sus familias al control constante, meticuloso, de sus acciones por parte de los creyentes y plantea el desafío de la sucesión del carisma. La falta persistente de continuadores obedece no sólo a la competencia encubierta entre sus potenciales herederos, sino también a la resistencia que demuestran muchas veces los mismos hijos de pastores a ocupar la posición de sus padres.

La orientación intra-mundana del ethos evangélico -contemplativo de las necesidades amorosas, la familia y el mundo del trabajo- potencia el desarrollo de los templos como fórmulas institucionales dinámicas, emergentes y -en más de un sentido- frágiles, es decir, expresiones o metáforas actuales del medio social que las rodea. Si captamos a los líderes y sus templos como programas inconclusos de acción, esto es, como procesos instituyentes de una espacialidad y una cronología compleja que encuentra su anclaje en el cruce entre esquemas interpretativos de orden general y las dificultades cotidianas de sus miembros, entonces es fácil entender la atracción que genera este dominio y conocimiento del territorio en distintos representantes de la sociedad civil: políticos, funcionarios públicos y comunicadores aceptan la auto-imagen que proyectan los pastores en tanto expertos sociales

\section{Revista Cultura \& Religión Vol. XIII, 2019 № 1 (enero-junio)}

Cómo citar este artículo: Mosqueira, M. \&Algranti, J. (2019). "Pastor, ¿usted en qué cree? Sociología de los procesos de liderazgo e institucionalización en iglesias evangélicas de pequeña y mediana escala”. Revista Cultura \& Religión. Vol.

13(1). pp. 85-103. 
de su barrio y las problemáticas que lo afligen. Aprender el juego de las instrumentalizaciones recíprocas entre la iglesia, el gobierno, los políticos en campaña y los medios de comunicación, implica explorar las valoraciones que se construyen entre los diversos agentes y las asimetrías desde donde se relacionan.

La respuesta sociológica a la pregunta del artículo -pastor, ¿usted en qué cree?- remite a la convicción primera de estos actores de asumirse y mostrarse de acuerdo a las exigencias tácitas de su cargo, es decir, como líderes de influencia, referentes morales para su comunidad, para el entorno, para los gobernantes. No se trata de una perfomance cínica, fingida, puro espectáculo, menos aún de un gesto exclusivamente utilitarista. Por el contrario, creer en la agencia del Evangelio, así como en las fuerzas que lo animan o el destino de liderazgo de sus seguidores, es creer en la capacidad de erigirse en tanto modelos generales de autoridad y reconocimiento. De este acto de confianza y demostración depende la posibilidad de proyectar impresiones exitosas de sus poderes sociales, una imagen capaz de ser convalidada al menos a grandes trazos y cuando las circunstancias convengan por otros dirigentes, pero del mundo secular.

\section{Referencias Bibliográficas}

Algranti, J. \& Mosqueira, M. (2018). "Sociogénesis de los dispositivos evangélicos de "rehabilitación" de usuarios de drogas en Argentina". Salud Colectiva, 14(2), pp. 305-322.

Algranti, J. (2010). Política y Religión en los márgenes: nuevas formas de participación social de las mega-iglesias evangélicas en la Argentina. Buenos Aires: Ciccus.

Algranti, J. (2018), "Objetos en acción. Estudio sobre instituciones, consumo y cultura material en el neo-pentecostalismo argentino". Estudios Sociológicos de El Colegio de México, 36(107), pp. 393-416.

Campos Machado, M. D. (1996). Carismáticos e Pentecostais. Adesão Religiosas na esfera familiar. Campinas: Ed. Autores Associados/ANPOCS.

Campos, R. \& Mauricio Junior, C. (2013) “As formas elementares da liderança carismática: o verbo e a imagética na circulação do carisma pentecostal”. Mana, 19(2), pp. 249276.

Carbonelli, M \& Mosqueira, M. (2008). "Luis Palau en Argentina: construcción mediática del cuerpo evangélico, disputa por el espacio público y nuevas formas de territorialidad", Enfoques, 20(2), pp. 65-87.

Carbonelli, M. (2011). “Ciencias Sociales, evangélicos y política. Una lectura sobre la producción científica acerca de la participación política evangélica en la vida democrática argentina (1983-2010)”. Cultura y Religión, 5(2), pp. 96-116.

Ceriani Cernadas, C. (2014). "Caleidoscopio del poder. Variedad del carisma en las iglesias indígenas del Chaco argentino". Miríadas, 6(10), pp. 9-36.

Revista Cultura \& Religión Vol. XIII, 2019 N 1 (enero-junio)

Cómo citar este artículo: Mosqueira, M. \&Algranti, J. (2019). "Pastor, ¿usted en qué cree? Sociología de los procesos de liderazgo e institucionalización en iglesias evangélicas de pequeña y mediana escala”. Revista Cultura \& Religión. Vol.

13(1). pp. 85-103. 
Duarte, L., Heilborn, M., Lins de Barros, M. \& Peixoto, C. (2006). Família e religião. Rio de Janeiro: Contracapa.

Durkheim, E. (1992). Las formas elementales de la vida religiosa. Madrid: Alianza.

Espinosa, M. \& Bargo, M. (2016). "Construir la iglesia de siempre. Estudio sobre la afirmación de identidades en el catolicismo y el evangelismo de la Argentina contemporánea". PLURA, Revista de Estudos de Religião, 7, pp. 201-222.

Feuchtwang, S. (2010). The Anthropology of Religion, Charisma, and Ghosts. Berlin: De Gruyter.

Freston, P. (2001). Evangelicals and Politics in Asia, Africa and Latin America, Cambridge: Cambridge University Press.

Frigerio, A. (1993). "La invasión de las sectas: el debate sobre nuevos movimientos religiosos en los medios de comunicación en Argentina". Sociedad y Religión, 10, pp. 24-51.

Frigerio, A. (2017). "Religion Out of Place: Social Regulation of Evangelical Expansion in Buenos Aires." En Secularisms in a Postsecular Age?: Religiosities and Subjectivities in Comparative Perspective ( $\mathrm{pp}$ 275-293). José Mapril, Ruy Blanes, Emerson Giumbelli y Erin K. Wilson (comps). New York: Palgrave Macmillan.

García Ruiz, J. \& Michel, P. (2012). Et Dieu sous-traita le salut au marché. Paris: A. Colins. Garma Navarro, C. (2000). "Del himnario a la industria de la alabanza. Un estudio sobre la transformación de la música religiosa", Ciencias Sociales y Religión, 2(2), pp. 63-85.

Giménez Béliveau, V. \& Mosqueira, M. (2011). "Lo familiar en las creencias y las creencias en lo familiar: Familia, transmisión y religión en la Argentina actual". Revista Cultura y Religión, 5(2), pp. 154-172.

Lago, L. (2018). Territorio de creencias: las prácticas culturales de los jóvenes pentecostales en la ciudad de Comodoro Rivadavia, Tesis de doctorado, Universidad Nacional de Quilmes, Argentina.

Latinobarómetro (2017). "El Papa Francisco y la religión en Chile y América Latina 1995 2017" Consultado el 8 de abril de 2019: http://www.latinobarometro.org/latNewsShow.jsp

Mallimaci, F., Esquivel, J \& Giménez Béliveau, V. (2015). "What do Argentine people believe in? Religion and social structure in Argentina". Social Compass, 62(2), pp. 255-277.

Mansilla Agüero, M. (2006). "Del valle de lágrimas al valle de Jauja. Las promesas redentoras del neopentecostalismo en el más acá". Polis, 14, pp. 1-16.

Mansilla Agüero, M. (2009). "De la caja del diablo a la caja de Dios. El neopentecostalismo chileno como iglesia electrónica". Penteco Studies, volumen 8, número 1, pp. 1-36.

Marostica, M. (1997). Pentecostals and politics: The creation of the evangelical Christian Movement in Argentina, 1983-1993. Tesis de doctorado, University of Berkeley, EEUU.

\section{Revista Cultura \& Religión Vol. XIII, 2019 № 1 (enero-junio)}

Cómo citar este artículo: Mosqueira, M. \&Algranti, J. (2019). "Pastor, ¿usted en qué cree? Sociología de los procesos de liderazgo e institucionalización en iglesias evangélicas de pequeña y mediana escala”. Revista Cultura \& Religión. Vol.

13(1). pp. 85-103. 
Miguel, G. (2013). “Género y enunciación evangélica en la producción cultural contemporánea". Cultura y Religión, 7(1), pp. 164-183.

Miguez, D. "Política y magia en un suburbio de Buenos Aires: estrategias indirectas de expresión de demandas en un contexto de clientelismo político". Sociedad y Religión, $16 / 17$, pp. 75-93.

Mosqueira, M. (2014). Santa rebeldia: construcciones de juventud en comunidades pentecostales del Área Metropolitana de Buenos Aires. Tesis de doctorado, Universidad de Buenos Aires, Argentina.

Mosqueira, M. (2016). "Hasta lo último de la tierra. Consolidación y transnacionalización del rock cristiano argentino". Sociology and Theory of Religion, 5(1), pp. 77-101.

Panotto, N. (2017). "Sí, tenemos una cosmovision política" Ethos, carisma e identidad en una iglesia pentecostal de Buenos Aires. Tesis de Maestría, FLACSO, Argentina.

Saracco, N. (1989). Argentine Pentecostalism: Its History and Theology. Tesis de doctorado, University of Birmingham, Inglaterra.

Semán, P. (2010). "De a poco mucho: las pequeñas iglesias pentecostales y el crecimiento pentecostal. Conclusiones de un estudio de caso", Cultura y Religión, (1), pp. 2-20.

Semán, P. (2013). "Pentecostalismo, política, elecciones y poder social". Cultura y Religión, 7(1), pp. 60-81.

Silveira Campos, L. (2012). "Bíblias no mercado: o poder dos consumidores e a competição entre os editores. O caso da sociedade bíblica do Brasil", Revista de Estudos da Religião, 12(2), pp. 35-61.

Soneira, A. (1991). El retorno de lo sagrado. Los movimientos evangelísticos en Argentina. Buenos Aires: Edición del autor.

Soneira, A. (1994). "Biografía y religiosidad pentecostal: una aproximación al estudio de las características socio-biográficas del creyente pentecostal”. En El pentecostalismo en la Argentina (pp. 44-60) A. Frigerio (Comp.). Buenos Aires: CEAL.

Soneira, A., Tort, I. \& Pessina, L. (1993). "El Ministerio Ondas de Amor y Paz del Pastor Héctor Aníbal Giménez". En Nuevos Movimientos Religiosos y Ciencias Sociales (pp. 49-80), A. Frigerio (Comp.). Buenos Aires: CEAL.

Spadafora A. (2004). Religión, política y estética. El pentecostalismo en la Argentina de los '90. Tesis doctoral. Universidad de Buenos Aires, Argentina.

Weber, M. (1998). Economía y Sociedad. México D.F: FCE.

Wynarczyk, H. (2007). Ciudadanos de dos mundos: la entrada de los evangélicos conservadores a la vida pública desde los 80 en la Argentina. Tesis de doctorado. Universidad Católica Argentina, Argentina.

Zaros, A. (2016). "Habitar la memoria a través de las generaciones. La transmisión religiosa en familias de diferentes credos en Padua", Estudos de Religião, 30(3), pp. 1-17.

Revista Cultura \& Religión Vol. XIII, 2019 Nº 1 (enero-junio)

Cómo citar este artículo: Mosqueira, M. \&Algranti, J. (2019). "Pastor, ¿usted en qué cree? Sociología de los procesos de liderazgo e institucionalización en iglesias evangélicas de pequeña y mediana escala”. Revista Cultura \& Religión. Vol.

13(1). pp. 85-103. 